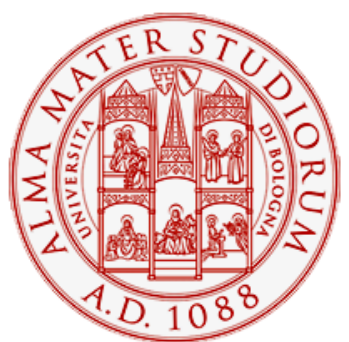

Alma Mater Studiorum - Università di Bologna DEPARTMENT OF ECONOMICS

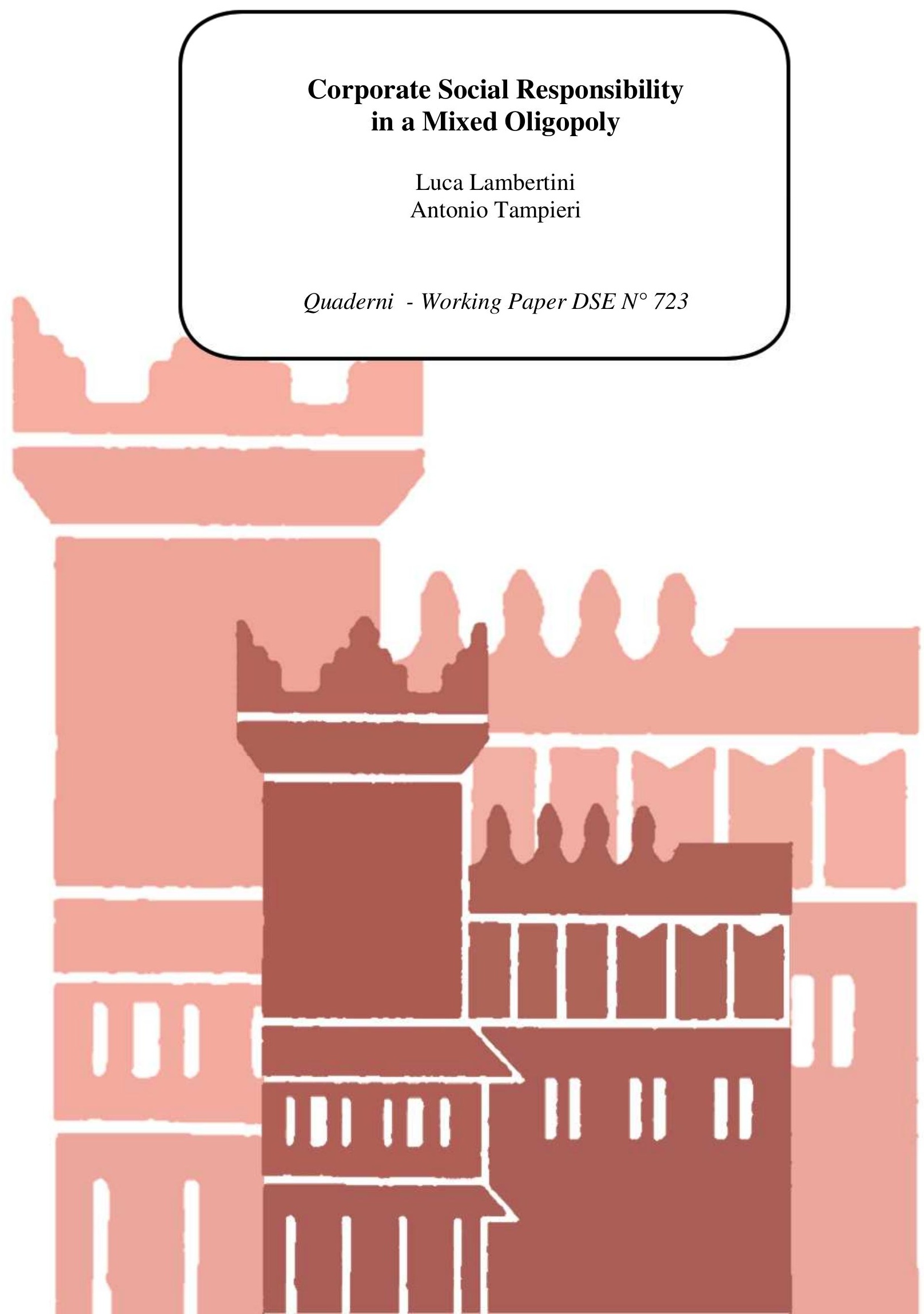




\title{
Corporate Social Responsibility in a Mixed Oligopoly*
}

\author{
Luca Lambertini ${ }^{\dagger}$ Alessandro Tampieri ${ }^{\ddagger}$ \\ University of Bologna
}

December 21, 2010

\begin{abstract}
This paper investigates how CSR firms influence a Cournot oligopoly with pollution. We define as CSR a firm that takes into account not only its profits but also internalises its own share of the externality and is sensitive to consumer surplus. The CSR firm obtains higher profits compared to profit-seeking firms. Also, the presence of at least one CSR firm improves social welfare and makes the first best Pigouvian taxation more lenient for Cournot firms. Finally, the CSR firm may induce the other firms to invest in "green" technology.
\end{abstract}

JEL Numbers: H23, L13, O31.

Keywords: CSR, green technology, environmental externality, Pigouvian taxation.

*We would like to thank Flavio Delbono, Luigi Alberto Franzoni, Arsen Palestini, Fausto Panunzi, Lorenzo Sacconi and the seminar audience at the conference Corporate Governance and Stakeholder Value: a Law and Economics Perspective, Bologna, for helpful suggestions and comments on an earlier draft. We also thank HERA spa for providing the research funds to this project. The usual disclaimer applies.

${ }^{\dagger}$ Department of Economics, University of Bologna, Strada Maggiore 45, 40125, Bologna, Italy; email: luca.lambertini@unibo.it.

${ }^{\ddagger}$ Department of Economics, University of Bologna, Strada Maggiore 45, 40125, Bologna, Italy; email: alessandro.tampieri@unibo.it. 


\section{Introduction}

Corporate Social Responsibility (CSR) is a form of corporate self-regulation. There is not a unique definition of Corporate Social Responsibility ${ }^{1}$, but we can summarise with the following: the CSR firm commits to a behaviour that takes into account not only the shareholder interests (profit), but also how the firm decisions affect the agents dealing with the firm (stakeholders), such as employees, business partners, consumers and environment. Along the years, the economic science mainly focused on the traditional profitmaximising view of the firm ${ }^{2}$ and only recently started paying attention to a vision of the firm based on CSR principles ${ }^{3}$.

In this paper we investigate how the presence of a CSR firm influences a Cournot oligopoly with pollution. We define as CSR a firm that takes into account not only its profits but also internalises its own share of the externality and is sensitive to consumers' welfare ${ }^{4}$.

We compare profits and social welfare of two industries. In the first one all the firms are profit-seekers while in the second one there is one CSR firm that cares also about its environmental impact and consumer surplus. The

\footnotetext{
${ }^{1}$ To cite some, for the World Business Council for Sustainable Development in its publication "Making Good Business Sense" (Holme and Watts), "Corporate Social Responsibility is the continuing commitment by business to behave ethically and contribute to economic development while improving the quality of life of the workforce and their families as well as of the local community and society at large". The CSR definition used by Business for Social Responsibility is "Operating a business in a manner that meets or exceeds the ethical, legal, commercial and public expectations that society has of business" . The European Commission hedges its bets with two definitions wrapped into one: "A concept whereby companies decide voluntarily to contribute to a better society and a cleaner environment. A concept whereby companies integrate social and environmental concerns in their business operations and in their interaction with their stakeholders on a voluntary basis"

${ }^{2}$ Friedman (1962 and 1970) argued that a corporation's purpose is to maximize returns to its shareholders, and that since only people can have social responsibilities, corporations are only responsible to their shareholders and not to society as a whole.

${ }^{3}$ For a discussion, see Benabou and Tirole (2010).

${ }^{4}$ Other approaches (Besley and Ghatak, 2010) identify CSR with creation of public goods or reducing in public bads.
} 
results show that, provided a large enough market, the CSR firm obtains a higher profit and improves social welfare. The intuition behind it is the following. The environmental concern restrains the CSR production, while the social concern expands it. The second effects more than offsets the first one in a large market, because the weight of a large number of consumers becomes stronger than the pollution weight. This makes the CSR production strategy be more aggressive compared to the competitors' strategy, and in turn leads the CSR profit to be higher than the profit-seeker profit and social welfare to improve.

We then investigate how the CSR influences the equilibrium when an anti-pollution first-best taxation policy takes place. The presence of at least one CSR firm makes the first best Pigouvian taxation more lenient for the other firms. This happens since the CSR strategy induces the competitors to lowers their output and thus their tax burden.

We finally analyse whether the CSR firm can influence the investments in "green" Research and Development. We show that the profit seeking firms invest in $\mathrm{R} \& \mathrm{D}$ in order to abate pollution because of the only presence of the CSR firm, which still acts as a self-regulating tool. The reason is that the CSR firm forces the remaining profit-seeking firms to take into account the environmental cost, then they are willing to minimise it through R\&D investments.

The remainder of the paper is organised as follows. Section 2 briefly discusses the related literature. Section 3 presents the model. Section 4 shows how the presence of a CSR firm influences the market equilibrium, profits and welfare. In Section 5 we study the first best taxation with and without a CSR firm in the industry. Section 6 examines whether the CSR firm can induce Cournot firms to invest in green technology. Section 7 concludes. 


\section{Related literature}

The paper can be related to three different branches of the economic literature, namely the literature on mixed oligopoly, efficiency inducing taxation and Corporate Social Responsibility.

After the seminal paper due to Merril and Schneider (1966), the literature on mixed oligopoly started developing only in the eighties ${ }^{5}$. De Fraja and Delbono (1989) showed that, if a public firm may wish to maximise industry welfare, its pursuit of this objective in interaction with private profit maximiser firm will lead to obtain a greater profit than that obtained by its otherwise identical private competitors. Cremer et al. (1989) suggest that to nationalise a single existing firm can be socially optimal if there are no other public firms in the industry, in some cases, nationalising the whole industry might be best, although unrealistic. De Fraja (1991) shows that the presence of a public firm in an oligopoly may improve the overall efficiency of the industry. This occurs as the low prices set by the public producer forces the private firms to cut their costs to match their prices. This effect is obtained even if the public firm has a certain grade of inefficiency compared to the private firm. Most recently, Matsumura and Matsushima (2004) elaborate this latest approach by endogenising production costs through cost-reducing activities. They show that the private firm cost becomes lower than the public firm cost because the former engages in excessive strategic cost-reducing activities. In relation to these contributions, we borrow the mixed oligopoly framework and substitute the CSR firm to the public firm.

In the literature on efficiency-inducing taxation, Bergstrom et al. (1981) examines the taxation of a monopolist supplier of a non-renewable resource. Both the government and the monopolist have complete information about demand, cost and reserves, and the government is assumed to use a linear taxation policy. They show that there is a group of tax-subsidy policies

\footnotetext{
${ }^{5}$ See De Fraja and Delbono (1990) for a survey.
} 
that would induce the monopolist to follow the efficient production path of a competitive industry. Karp and Livernois (1992) show that an efficiencyinducing taxation result can be obtained also by relaxing the assumption of the government complete information about the monopolist cost function and reserves. Karp and Livernois (1994) examine the problem of knowing the level of pollution abatement in the absence of information about abatement costs. They show that the problem can be solved through an iterative procedure in which the tax is adjusted when current emission exceed or fall short of the target. Benchekroun and Long (1998 and 2002) examine the design of a taxinducing system in an oligopolistic and monopolistic industry. They show that there always exists a tax rule leading oligopolists (monopolist) to reach the socially optimum production level. Like in this literature, in Section 5 we study the first best taxation to prevent the negative externality.

The literature on CSR only recently started developing in the economic literature. One strand identifies CSR with creation of public goods or curtailment of public bads (Bagnoli and Watts, 2003, Kotchen, 2006, Besley and Ghatak, 2010), generally showing that there is a close parallel between CSR so defined and the results obtained by the models of private provision of public goods. Other contributes study the desirability of CSR (Baron, 2001), the role of CSR in selecting motivated agents (Brekke and Nyborg, 2005) or the firm competition in the presence of "green" consumers. (Arora and Gangopdhyay, 1995).

\section{The model}

We study a static oligopoly market with $n>2$ firms. Firms supply a homogeneous good, whose market demand function is $p=a-Q, a$ being a positive constant parameter measuring the reservation price and $Q=\sum_{i=1}^{n} q_{i}$ being the sum of all firms' individual output levels $q_{i}$. Production takes place at constant returns to scale with a marginal cost $c \in(0, a)$, common to all 
firms. Hence firm $i$ 's profit function will be $\pi_{i}=(p-c) q_{i}$.

The production of the final output goes along with a negative environmental externality $E=g Q$, where $g>0$ represents the marginal polluting intensity of output. Consumer surplus is measured by $C S=Q^{2} / 2$. Social welfare is defined as the sum of industry profits and consumer surplus, minus pollution:

$$
W=\sum_{i=1}^{n} \pi_{i}+\frac{Q^{2}}{2}-g Q
$$

Throughout the paper, for notational simplicity we shall define the market size as $m=a-c$.

Initially we consider the case with $n$ profit-maximising firms competing à la Cournot-Nash. We will refer to these as "Cournot firms". The market equilibrium is the traditional Cournot result and it is given by:

$$
q_{C N}=\frac{m}{1+n}
$$

Individual equilibrium profits are:

$$
\pi_{C N}=\left(\frac{m}{1+n}\right)^{2}
$$

Correspondingly, consumer surplus is:

$$
C S_{C N}=\frac{1}{2}\left(\frac{m}{1+n}\right)^{2}
$$

and social welfare is:

$$
W_{C N}=\left(\frac{(2 n+1)}{2}\left(\frac{m}{1+n}\right)-g\right)\left(\frac{m}{1+n}\right) .
$$

Consider now the same industry with $n-1$ Cournot firms denoted as $i \in\{1,2, . ., j-1, j+1, \ldots n\}$, and a single CSR firm, denoted as $j \in\{1, \ldots, n\}$. According to the "European Union Paper on Corporate Social Responsibil- 
ity" , CSR companies integrate social and environmental concerns in their business operations. Within the company, socially responsible practices primarily involve employees and relate to issues such as investing in human capital, health and safety, and managing change, while environmentally responsible practices relate mainly to the management of natural resources used in the production. Out of the company, CSR practices involve a wide range of stakeholders: business partners and suppliers, customers, public authorities and local communities, as well as the environment.

Thus we need to assume a specific CSR objective structure. For the environmental concern, we assume that the CSR firm internalises its own share of pollution. All the other social concerns can be interpreted in our model as part of consumer surplus, hence we assume that the CSR firm is sensitive to it. Thus the CSR objective function is:

$$
\tilde{\pi}_{j}=\pi_{j}-g q_{j}+\frac{z\left(q_{j}+Q_{-j}\right)^{2}}{2}
$$

where $Q_{-j}=\sum_{i \neq j} q_{i}$ and $z \in[0,1]$ denotes the weight that firm $j$ assigns to consumer surplus.

To begin with, we would like to dwell upon the features of first order conditions and the resulting map of best replies. The behaviour of any of the $n-1$ Cournot firms is altogether standard, and is summarised by the best reply function:

$$
q_{i}^{*}=\frac{m-Q_{-i}}{2} .
$$

On the other hand, the CSR's reaction function explicitly incorporates its concerns about consumer surplus and environmental effects:

$$
q_{j}^{*}=\frac{m-g-(1-z) Q_{-j}}{2-z} .
$$

the above reaction function is flatter than a standard Cournot best reply, 
since:

$$
\left|\frac{\partial q_{j}^{*}}{\partial Q_{-j}}\right|=\frac{1-z}{2-z}<\frac{1}{2} \quad \text { always }
$$

with

$$
\left|\frac{\partial^{2} q_{j}^{*}}{\partial Q_{-j} \partial z}\right|=-\frac{1}{(2-z)^{2}}<0,
$$

for all admissible values of $z$. Moreover, the intercept of $q_{j}^{*}$ along the axes of $q_{j}$ is

$$
\left.q_{j}^{*}\right|_{Q_{-j}=0}=\frac{m-g}{2-z} \gtrless \frac{m}{2}, \text { for all } \quad m \gtrless \frac{2 g}{z} .
$$

On this basis, we may offer a preliminary qualitative assessment of the CSR firm's attitude in the following terms:

Lemma 1 The CSR's best reply is flatter than that of any of its Cournot rivals, and becomes increasingly flatter as $z$ increases. The monopoly output of the CSR is larger (resp., lower) than the pure profit-seeking monopoly output for all $m>2 g / z$ (resp. $m<2 g / z t)$.

The above Lemma deserves a few comments. On the one hand, all else equal, flattening the best reply entails that the output decision of the CSR firm becomes less sensitive to any change in the rivals' output, and therefore we shall expect to observe a sort of more aggressive behaviour on its part, than what would otherwise emerge from a strict profit-seeking behaviour. On the other hand, the intercept of the CSR firm's reaction function shifts up or down depending on market size. If the market is large enough, the inclusion of corporate social responsibility in the statute of the firm necessarily brings about the consequence that the CSR will produce more than a standard Cournot unit (because the function is flatter and the intercept is higher). If, conversely, the market is below the critical threshold, the balance between the two effects is a priori ambiguous. 
Figure 1. Lemma 1.

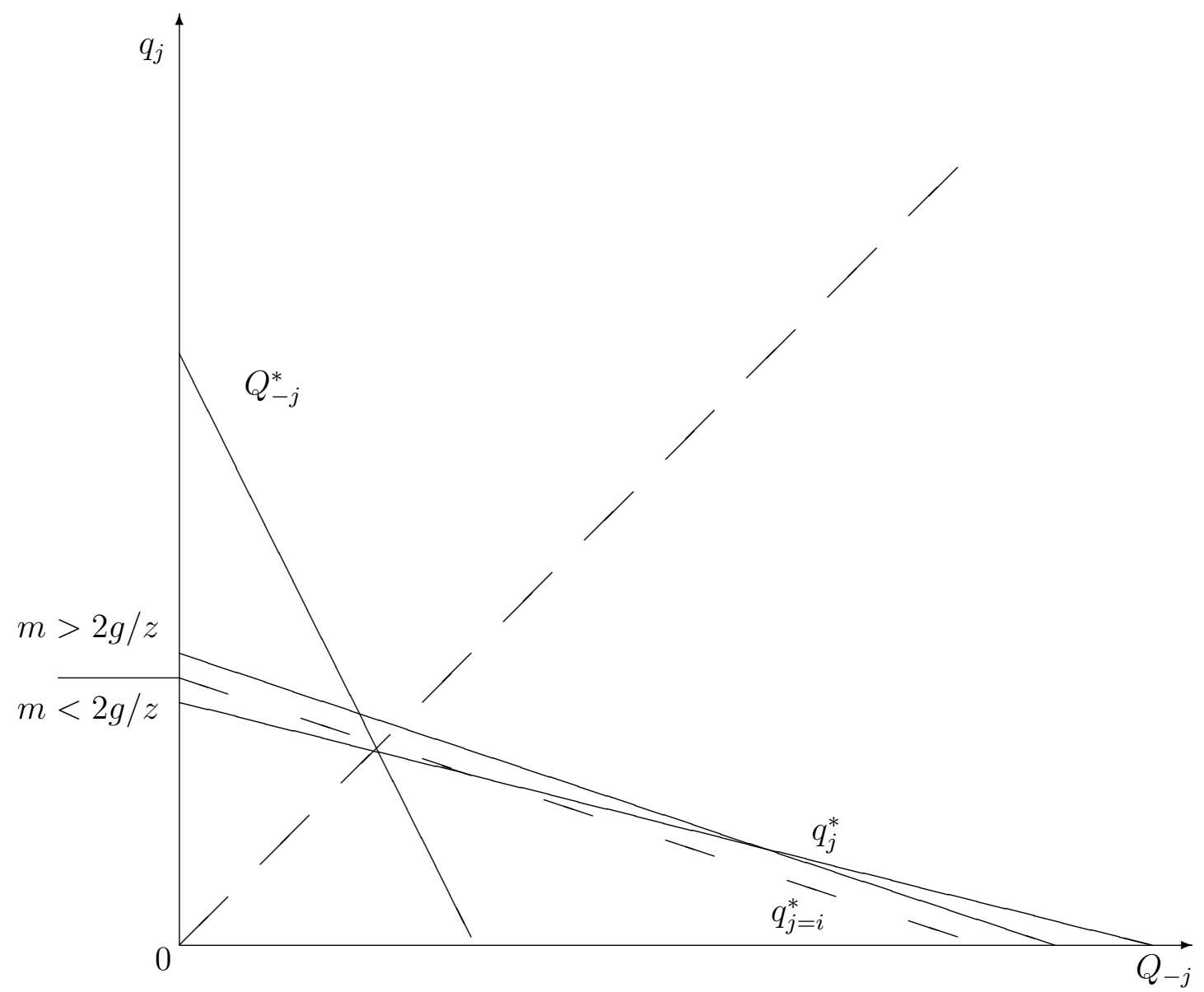

Now we can proceed to characterise the market equilibrium. The firms' optimal outputs are given by:

$$
q_{j}=m-\frac{n(m(1-z)+g)}{1+n-z}
$$

and

$$
q_{i}=\frac{m(1-z)+g}{1+n-z}
$$


The CSR-firm profits are:

$$
\pi_{j}=\frac{(m(1-z)+g)(m((n-1) z+1)-g n)}{(1+n-z)^{2}},
$$

while the profits of any individual Cournot firm are:

$$
\pi_{i}=\frac{(m(1-z)+g)^{2}}{(1+n-z)^{2}}
$$

Consumer surplus is:

$$
C S_{C S R}=\frac{(g-m n)^{2}}{2(1+n-z)^{2}}
$$

and social welfare amounts to:

$$
W_{C S R}=\frac{(g-m n)(m(2 z-2-n)+2 g(n-z))}{2(1+n-z)^{2}} .
$$

\section{Results}

In this section we show how the presence of the CSR modifies the equilibrium performance of the industry. The following proposition focusses on profits and social welfare.

Proposition 1 The necessary and sufficient condition ensuring that $\pi_{j}>\pi_{i}$ and $W_{C S R}>W_{C N}$ is that

$$
m>\max \left\{\frac{g(1+n)}{n z}, \frac{g(1+n)(1+2(n-z))}{n(2-z)+2(1-z)}\right\},
$$

with

$$
\max \left\{\frac{g(1+n)}{n z}, \frac{g(1+n)(1+2(n-z))}{n(2-z)+2(1-z)}\right\}=\frac{g(1+n)}{n z},
$$

for all $n z<1$, and

$$
\max \left\{\frac{g(1+n)}{n z}, \frac{g(1+n)(1+2(n-z))}{n(2-z)+2(1-z)}\right\}=\frac{g(1+n)(1+2(n-z))}{n(2-z)+2(1-z)}
$$


for all $n z>1$.

Proof. First, we need to ensure that profits are positive. This is true for all $m>g(1+n) /(n z)$. Then, consider $W_{C S R}-W_{C N}$, which is a quadratic expression in $m$. It is then a matter of trivial algebra to check that $W_{C S R}=W_{C N}$ in $m=g(1+n) /(n z)$ and $m=g(1+n)(1+2(n-z)) /[n(2-z)+2(1-z)]$, $W_{C S R}-W_{C N}$ being positive for external values.

Case I: if $n z<1$, then

$$
\frac{g(1+n)}{n z}>\frac{g(1+n)(1+2(n-z))}{n(2-z)+2(1-z)} .
$$

The profit difference is

$$
\pi_{j}-\pi_{i}=\frac{(g-m(z-1))((m n z-g(1-n))}{(1+n-z)^{2}}
$$

which is positive for all $m>g n /(1+(n-1) z)$, with

$$
\frac{g n}{1+(n-1) z}<\frac{g(1+n)}{n z}
$$

always. Therefore, in this region

$$
m>\frac{g(1+n)}{n z}
$$

is necessary and sufficient to ensure both $\pi_{j}>\pi_{i}$ and $W_{C S R}>W_{C N}$.

Case II: if $n z>1$, then

$$
\frac{g(1+n)(1+2(n-z))}{n(2-z)+2(1-z)}>\frac{g(1+n)}{n z}
$$

Consequently, in this region, $\pi_{j}>\pi_{i}$ and $W_{C S R}>W_{C N}$ for all $m>g(1+$ $n)(1+2(n-z)) /[n(2-z)+2(1-z)]$. 
Figure 2. Proposition 1.

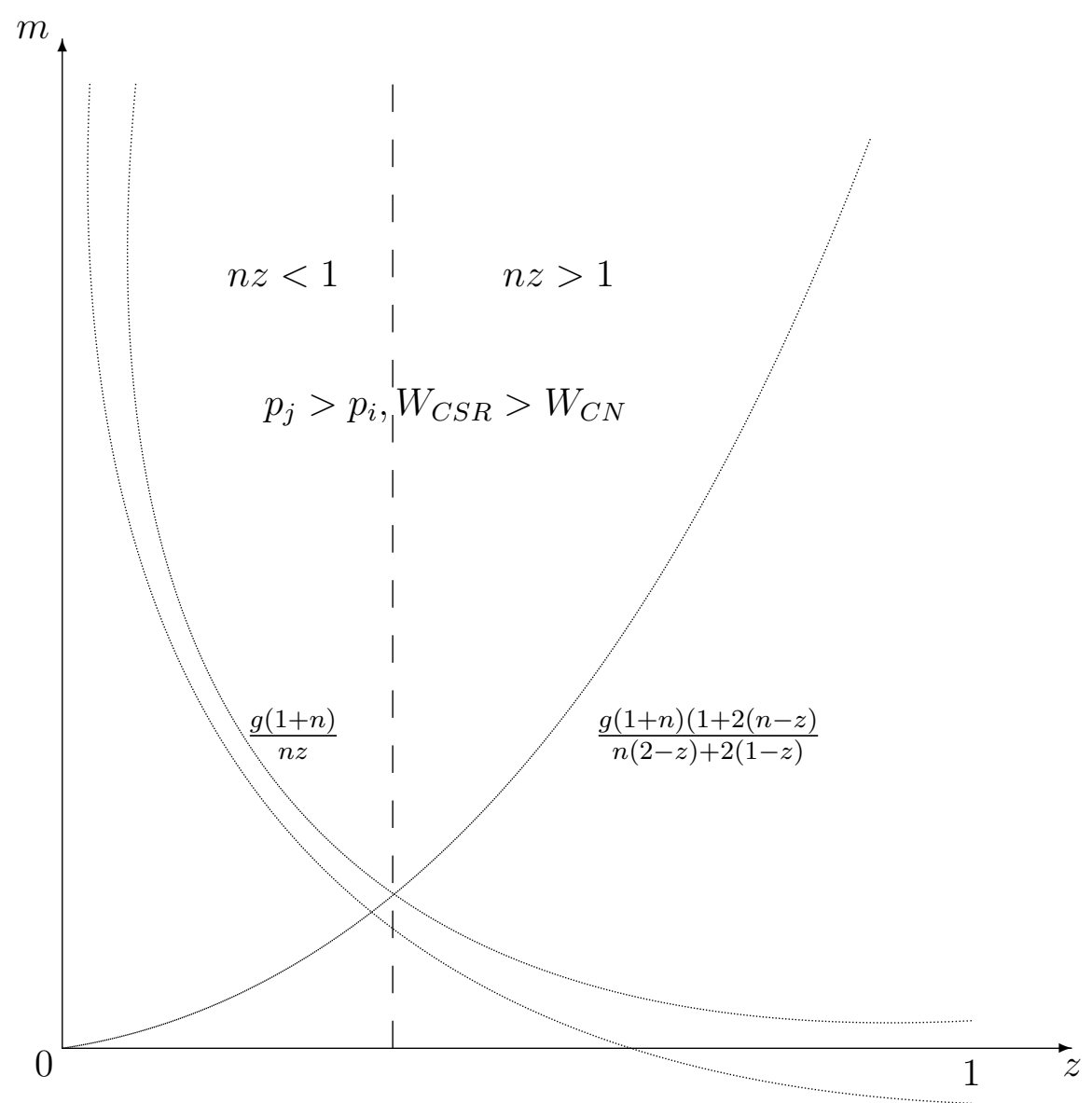

Figure 2 illustrates Proposition 1. The vertical dashed line separates the area where $n z<1$ from that in which $n z>1$. Proposition 1 shows that, in a large enough market, it is more profitable being a CSR rather than a Cournot firm. Also, the presence of a CSR firm can improve social welfare as compared to a situation in which all firms are pure profit-seeking agents. The reason is that the presence of the CSR firm forces the remaining profit-seeking firms to take into account both the negative environmental externality and consumer surplus, although only indirectly via the intersection of best reply functions. 
The results of Proposition 1 change according to whether the CSR assigns a high or low weight to consumer surplus, i.e., if $n z$ is greater or smaller than one. However, the message behind the results does not change irrespective of $n z$.

\subsection{Comparative statics}

In this section we examine how the CSR's weight assigned to consumer surplus $z$ affects both the CSR and the Cournot-firms profit. The following corollary shows these comparative statics properties.

Corollary 1 If $n<\frac{(1-z)}{(1-2 z)}$, the CSR-firm profit increases as $z$ increases if $m>\frac{g}{n}$ and decreases otherwise; if $n>\frac{(1-z)}{(1-2 z)}$, the CSR profit increases as $z$ increases if $m>\frac{2 g n}{1-z-n(1-2 z)}$ or $m<\frac{g}{n}$ and diminishes otherwise. The Cournot-firm profit increases as $z$ increases if $m<\frac{g}{n}$ and diminishes otherwise.

Proof. Differentiation of $\pi_{j}$ with respect to $z$ yields $\frac{\partial \pi_{j}}{\partial z}=\frac{(m n-g)(2 g n+m(n-1+z-2 n z))}{(1+n-z)^{3}}$. Solving by $m$, we have 2 solutions, $\frac{g}{n}$ and $\frac{2 g n}{1-z-n(1-2 z)}$. The derivative is positive for external values to the solutions. If $n<\frac{(1-z)}{(1-2 z)}$, the second solution is negative, so the derivative is positive when $m>\frac{g}{n}$. If $n>\frac{(1-z)}{(1-2 z)}$, the former is higher than the latter and both solutions are positive. Differentiation of $\pi_{i}$ with respect to $z$ yields $\frac{\partial \pi_{i}}{\partial z}=\frac{(m n-g)(g+m(1-z))}{(1+n-z)^{3}}$, which is always positive for $m<\frac{g}{n}$.

Following Corollary 1, the CSR sensitivity to consumer surplus affects profits differently according to the firm type.

For the CSR firm the relationship between the firm profit and $z$ is related both on the market size and on the number of firms in the market. In particular, with few firms, the relationship is positive given a large market size. With a large number of firms, the relationship is positive with a small market size. 
For the Cournot firms, the CSR sensitivity to consumer surplus is positively related to its profits if the market is small and negatively related if the market is large, irrespective of the number of firms in the industry.

\section{CSR with Cournot-taxation and first best}

In this section we study the introduction of an anti-pollution first-best taxation. Again, we compare the case with all Cournot firms to the case with one CSR firm and $n-1$ Cournot firms. In the second case, only the Cournot firms pay the Pigouvian tax. Indeed the CSR firm is exempted since it internalises its own pollution.

With $n$ Cournot firms, their profit function is:

$$
\pi=(p-c) q-\tau E
$$

where $\tau \in[0,1]$ is the tax rate, and the consumer surplus becomes $C S_{\tau}=$ $\frac{Q^{2}}{2}+n \tau E$. The market equilibrium is reached when $q_{C N \tau}=\frac{m-g \tau}{1+n}$, and social welfare is $W_{C N \tau}=\frac{n(m(2+n)+g(n(\tau-2)-2))(m-g \tau)}{2(1+n)^{2}}$. The first best taxation is obtained by maximising $W_{C N \tau}$ with respect to $\tau$, which yields $\frac{g n(g(1+n-n \tau)-m)}{(1+n)^{2}}=$ 0 . Thus the first best tax rate is $\tau_{C N}=\frac{g(1+n)-m}{g n}$. By substituting $\tau_{C N}$ in $W_{C N \tau}$, we obtain the first best social welfare defined as $W_{F B}=\frac{(g-m)^{2}}{2}$.

Consider now the case where $n-1$ Cournot firms pay a tax $t$. Consumer surplus now is $C S_{t}=\frac{Q^{2}}{2}+(n-1) t E$. The market equilibrium is reached when the quantities are $q_{i t}=\frac{m(z-1)+g(2(n-1) t-1)}{(n-1)(z-3)}$ for all $i \in\{1,2, . ., j-1, j+1, \ldots n\}$ and $q_{j t}=\frac{g(2(n-1) t(1+z))-m(z-1)}{(n-1)(z-3)}$. Social welfare is:

$$
W_{C S R t}=\frac{(g(1-t(n-1)(z-1))-2 m)(2 m(z-2)+g(5+t(n-1)(z-1)-2 z))}{2(z-3)^{2}} .
$$

The level of $t$ that guarantees the first best is obtained by equating $W_{C S R t}$ to $W_{F B}$. By solving for $t$ we have $t_{C S R}=\frac{m(1-z)+g(z-2)}{g(n-1)(z-1)}$. We define as $\pi_{j t}$ and 
$\pi_{i t}$ the profits of the CSR and Cournot firm, respectively, when $t=t_{C S R}$. The following proposition shows the properties of this market equilibrium.

Proposition 2 If $m>\frac{2 g-g z+g(z(4-3 z))^{\frac{1}{2}}}{2(1-z)}$, then:

(i) profits are positive for every firm in the market;

(ii) $t_{C S R}$ is positive;

(iii) $\tau_{C N}>t_{C S R}$;

(iv) if $m<\frac{2 g-g z+g(z(4 n(1-z)+z))^{\frac{1}{2}}}{2(1-z)}$, then $\pi_{j t}>\pi_{i t}$

Proof. First, we need to ensure that profits are positive. By substituting $t_{C S R}$ in the CSR-firm profit, we obtain $\pi_{j t}=\frac{z g^{2}}{1-z}$, which is always positive. By substituting $t_{C S R}$ in the Cournot-firm profit, we obtain $\pi_{i t}=\frac{m^{2}+g^{2}+m g \frac{2-z}{z-1}}{n-1}$. This is positive if $m>\frac{2 g-g z+g(z(4-3 z))^{\frac{1}{2}}}{2(1-z)}$. Then consider when $t_{C S R}>0$. This occurs for all $m>\frac{g(z-2)}{1-z}$. Finally, the case where $\tau_{C N}>t_{C S R}$ is verified for all $m>\frac{g\left(1-n(z-2)+n^{2}(z-1)-z\right)}{1-z}$. By comparing the three critical point, it is possible to see that if $m>\frac{2 g-g z+g(z(4-3 z))^{\frac{1}{2}}}{2(1-z)}$ all the properties hold. Finally, $\pi_{j t}>\pi_{i t}$ for all $m<\frac{2 g-g z+g(z(4 n(1-z)+z))^{\frac{1}{2}}}{2(1-z)}$. This is always higher than $\frac{2 g-g z+g(z(4-3 z))^{\frac{1}{2}}}{2(1-z)}$ so a range exists where $\pi_{j t}>\pi_{i t}$.

Figure 3 shows Proposition 2. On the right of $m_{2}$ firms cannot obtain positive profits. On the left of $m_{1}$ every profit is positive, and the unitary tax paid by the Cournot firms is lower in the presence of a CSR firm. Inbetween the two curves the profit obtained by a CSR firm is higher than the profit obtained by a Cournot firm.

The main result of Proposition 2 is that the tax burden of profit-seeking firms is more lenient given the presence of a CSR firm. Thus the presence of a CSR firm in the industry may be desirable for their competitors also. 
Figure 3. Proposition 2.

$$
\begin{aligned}
& m_{1}=\left(\left(2 g-g z+g(z(4-3 z))^{(1 / 2)}\right) /(2(1-z))\right) \\
& m_{2}=\left(\left(2 g-g z+g(z(4 n(1-z)+z))^{(1 / 2)}\right) /(2(1-z))\right)
\end{aligned}
$$

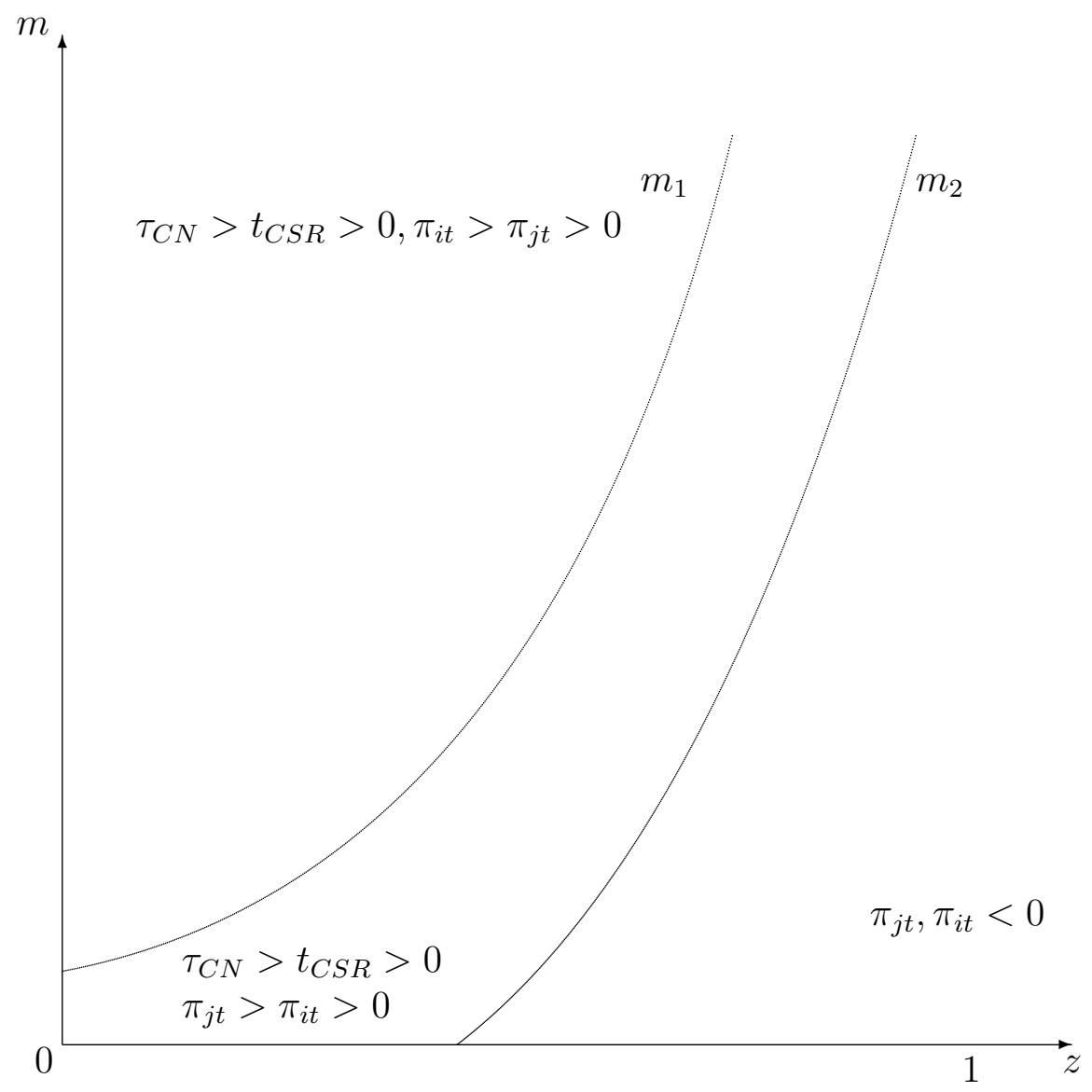

\section{CSR and R\&D}

In this section we investigate whether the presence of a CSR firm can induce Cournot firms to invest in "green Research and Development" (from now on, R\&D). To do so, we consider a previous stage of the game where firms can undertake costly R\&D projects.

We rewrite the Cournot-firms profit function as $\pi_{i R D}=(p-c) q_{i}-b k_{i}^{2}$ 
and the CSR-firm objective function as:

$$
\tilde{\pi}_{j}=\pi_{j}-g q_{j}+\frac{z\left(q_{j}+Q_{-j}\right)^{2}}{2}-b k_{j}^{2}
$$

where $k_{i, j}>0$ is the amount of investment in R\&D of a Cournot and CSR firm, respectively, and $b>0$ is a parameter. Finally, we assume that the intensity of the output in polluting environment is now measured by $g=$ $\bar{g}-\sum^{n-1} k_{i}-k_{j}$, where $\bar{g}$ is the highest level of pollution intensity, which occurs when no R\&D actions take place whatsoever. Thus the investment in R\&D diminishes the impact of the output in polluting. Our modelisation relies on the simplifying assumption that the green innovation is a public good freely appropriable by all firms alike without legal consequences whatsoever.

We solve the problem by backward induction. The market equilibrium in the second stage of the game is still given by Eq. (12) and Eq. (13) with the new assumptions on $g$.

In the first stage, firms decide their optimal R\&D investment. We can easily notice that, in absence of a CSR firm, the Cournot firms' investments in $R \& D$ would be nought. The reason is that the first order condition of $\pi_{i R D}$ in the first stage of the game with only Cournot firms is clearly $-2 b k_{i}=0$, thus $k_{i}=0$. A remedy could be the introduction of Pigouvian taxation by a regulator, as shown in Poyago-Theotoky (2007).

Consider now the presence of the CSR firm in the industry. The first order condition of $\tilde{\pi}_{j}$ with respect to $k_{j}$ yields to $-2 b k_{j}=0$, thus the optimal investment in R\&D for a CSR firm is zero. This is intuitive. The CSR firm already incorporated the cost of pollution in its output decisions, so investing in $R \& D$ would be like paying for it twice.

Let us turn on the Cournot firms. The first order condition of $\pi_{i R D}$ with respect to $k_{i}$ yields:

$$
\frac{2\left(m(z-1)+k_{i}+k_{w}(n-2)-\bar{g}\right)}{(n+1-z)^{2}}-2 b k_{i}=0,
$$


where $k_{w}, w \neq i, j$, is the $\mathrm{R} \& \mathrm{D}$ investment of the Cournot firms different from $i$.

The following lemma tells us for which parameter values the solution is a maximum point.

Lemma 2 We are in a maximum point if and only if $b \geq \frac{1}{(n+1-z)^{2}}$.

Proof. The second order condition of $\pi_{i R D}$ with respect to $k_{i}$ yields $-2 b+$ $\frac{2}{(n+1-z)^{2}} \leq 0$. This is satisfied by all $b \geq \frac{1}{(n+1-z)^{2}}$.

In equilibrium, all Cournot firms make identical choices in $R \& D$ investment because of their a priori symmetry, $k_{i}=k_{w}=k$. Using it in (26) and solving, we obtain:

$$
k^{*}=\frac{m(1-z)+\bar{g}}{n-1-b(1+n-z)^{2}}
$$

From this result we can derive the following Proposition.

Proposition 3 For $b \geq \frac{1}{(n+1-z)^{2}}$, the presence of a CSR firm induces Cournot firms to invest in R\&D.

Proof. As we previously stated, with no CSR firms the investment in R\&D for a Cournot firm is zero. The proposition is true if $k^{*}>0$. We can notice that the numerator is always positive, since $z<1$, and so is the denominator. Hence $k^{*}>0$ is always positive.

The presence of the CSR firm is sufficient by itself to induce profit seeking firms to invest in R\&D, without any need of government regulation. The intuition lies in the same argument considered in Section 4. The CSR forces Cournot firms to implement pollution as a negative element within their reaction function. This gives them an incentive to invest in $R \& D$ to minimise the pollution cost. 


\section{Conclusion}

This paper investigates how the presence of a CSR firm influences a Cournot oligopoly with pollution. In a large market, a CSR firm has higher profits than a profit-seeking firm, and its presence improves social welfare. Yet, at least one CSR firm makes the first best Pigouvian taxation more lenient for Cournot firms. We finally consider whether the CSR firm can influence the investments in "green" technology. We show that the profit-seeking firms invest in $\mathrm{R} \& \mathrm{D}$ in order to abate pollution because of the only presence of the CSR firm, which still acts as a self-regulating tool.

We have assumed that firms cannot change type. The presence of a CSR firm may induce other pure profit-seeking units to adopt a CSR statute as well. The analysis of this perspective and its consequences in the evolution of the industry is left for future research.

\section{References}

[1] Arora, S. and Gangopadhyay, S. 1995. Toward a theoretical model of voluntary overcompliance. Journal of Economic Behavior and Organization 28: 289-309.

[2] Baron, D. 2001.Private politics, Corporate Social Responsibility, and integrated strategy. Journal of Economic Management and Strategy 10 (1). In Marchand, M., Pestieau, P. and Tukens, H (eds). The performance of public enterprises. North Holland, Amsterdam.

[3] Beato, P. and Mas-Colell, A. 1984. The marginal Cost pricing as a regulation mechanism in mixed markets.

[4] Benchekroun, H. and Van Long, N. 1998. Efficiency inducing taxation for polluting oligopolists. Journal of Public Economics 70: 325-342. 
[5] Benchekroun, H. and Van Long, N. 2002. On the multiplicity of efficiency inducing tax rules. Economics Letters 76: 331-336.

[6] Bergstrom, T. C., Cross, J. G. and Porter, R. C. 1981. Efficiencyinducing taxation for monopolistically supplied depletable resource. Journal of Public Economics 15: 23-32.

[7] Besley, T. and Ghatak, M. 2010. Retailing Public Goods: The Economics of Corporate Social Responsibility. Journal of Public Economics 91(9): 1645-1663.

[8] Cremer, H., Marchand, M., Thisse, J.F. 1989. The public firm as an instrument for regulating an oligopolistic market. Oxford Economic Papers 41: 283-301.

[9] Cremer, H., Marchand, M., Thisse, J.F. 1991. Mixed oligopoly with differentiated products. International Journal of Industrial Organization 9: 43-53.

[10] De Fraja, G. and Delbono, F. 1989. Alternative Strategies of a Public Enterprise in Oligopoly. Oxford Economic Papers 41(2): 302-11.

[11] De Fraja, G. and Delbono, F. 1990. Game Theoretic Models of Mixed Oligopoly Journal of Economic Surveys 4(1): 1-17.

[12] De Fraja, G., 1991. Efficiency and Privatisation in Imperfectly Competitive Industries Journal of Industrial Economics 39(3): 311-21.

[13] Friedman M. 1970. The social responsibility of business is to increase its profits. New York Times Magazine 13, pp. 122-126.

[14] Friedman M. Capitalism and Freedom. University of Chicago Press, 1962. 
[15] Karp, L. and Livernois, J. 1992. On efficiency-inducing taxation for a nonrenewable resource monopolist. Journal of Public Economics 49: 219-239.

[16] Karp, L. and Livernois, J. 1994. Using automatic tax changes to control pollution emissions. Journal of Environmental Economics and Management 27: 38-48.

[17] Matsumura, T. and Matsushima, N. 2004. Endogenous cost differential between public and private enterprises: a mixed duopoly approach. Economics 71: 671-688.

[18] Merrill, W. and Schneider, N. 1966. Government firms in oligopoly industries: a short-run analysis. the Quarterly Journal of Economes 80: 400-412.

[19] www.mallenbaker.net/csr/definition.php.

[20] Poyago-Theotoky, J. 2007. The organization of R\&D and environmental policy. Journal of Economic Behaviour and Organization 62: 63-75. 


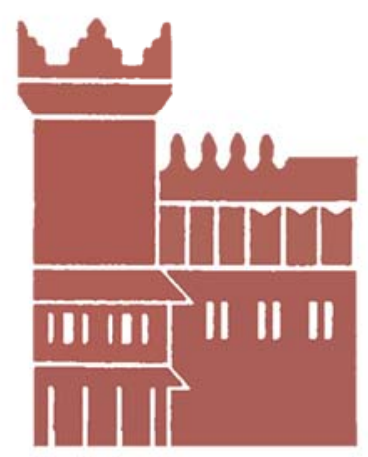

Alma Mater Studiorum - Università di Bologna DEPARTMENT OF ECONOMICS

Strada Maggiore 45

40125 Bologna - Italy

Tel. +39051 2092604

Fax +390512092664

http://www.dse.unibo.it 